\title{
How the Legal Status of Undocumented Students Affects Their Access to Higher Education, Public Health and Mental Health Services
}

\author{
James T. Decker, Ph.D., LCSW \\ Professor \\ Hyun Sun Park, Ph.D. \\ Associate Professor \\ Wendy Ashley, Psy.D, LCSW \\ Associate Professor \\ Department of Social Work \\ California State University, Northridge \\ Northridge California \\ Christy Bame, MSW \\ Research Assistant \\ Tarzana Treatment Centers \\ Tarzana, CA
}

\begin{abstract}
This descriptive study examines the stories of 102 university students ( $71 \%$ female and $29 \%$ male) and the effects of their legal status on their access to public health, mental health and higher education services. Literature on the immigrant community and their struggles due to their legal status as undocumented individuals is reviewed and supported by the current research. Seventy-six percent identify as benefitting from employment authorization through Deferred Action for Childhood Arrivals (DACA) and 24\% with no protective status. Due to the perceived fear across generations that continues to exist among the undocumented population, it is hypothesized that those who identify as undocumented will be less likely to have access to services than those who identify with any type of legal status including DACA as a protective status. However, as university students are being interviewed, positive reinforcements on this pool of participants may contribute to a higher access of services when compared to the general undocumented population. This study uses a mixed methods approach with general demographics and an interview-structured questionnaire through Qualtrics
\end{abstract}

\section{Introduction}

Latin American and Asian foreign-born populations in the United States are the fastest growing, having doubled from 20 million in 1990 to 40 million in 2010 (U.S. Census Bureau, 2013). Members of the immigrant community who identify or have identified as undocumented at some point in their lives have been influenced by fear due to their undocumented status when accessing public services (Berk \& Schur, 2001). In 1994, the passage of Proposition 187 in California ignited the already-perceived fear by the immigrant community in accessing services as public workers were required to report undocumented immigrants to immigration authorities (Berk \& Schur, 2001). Fears ignited by the uncertainty of trusting public services' professionals continued to be influenced by the immigrant community's limited English proficiency (Kim, Aguado, Chiriboga, Jang, Parmelee \& Allen, 2010). The number of immigrants who spoke English "less than very well" in 1980 rose from $43 \%$ to $50 \%$ in 2013 (Pew Research Center, 2017). According to Pew Research Center, an estimated 30\% of immigrants (11 million) are undocumented and living without the proper paperwork in the United States as of 2017. From that statistic, as of September $4^{\text {th }}, 2017,690,000$ unauthorized immigrants are currently under Deferred Action for Childhood Arrivals (DACA) legislature (Pew Research Center, 2017). In 2011, DACA (Schmid, 2013) awarded temporary deportation relief and work employment authorization to young adults who were brought to the US illegally as children and met DACA requirements beginning June 15, 2012, granting approval to over 665,000 applicants (Pew Research Center, 2017). 
The legal status of individuals affects their family life, health care, housing conditions, romantic relationships, higher education, employment opportunities and increases fear, anxiety and stress (Gonzales, Terriquez \& Ruszczyk, 2014). Individuals who were granted DACA status have the potential of benefitting from new opportunities and realizations.

\section{Public Health Services}

The Hispanic population is growing rapidly with 1 in every 5 children being Hispanic (Avila \& Bramlett, 2012). According to the Maternal and Child Health Bureau (2009), there is an estimated 19\% of Hispanic children who do not have health insurance coverage in comparison to $6 \%$ of the non-Hispanic white population. Research has found that parents who are not proficient in English-speaking skills are also less likely to visit the doctor and more likely to report a dissatisfaction in health care providers or services (Flores, Tomany-Korman \& Abren, 2008). When comparing non-Hispanic to white children, Hispanic children are 4 times as likely to be rated with fair or poor overall health, as well as dental health, and 3 times as likely to have no health care insurance (Avila \& Bramlett, 2013). They are also more likely to have a higher need of medical attention and higher risk of developmental delays (Avila \& Bramlett, 2013).

Medical attention needs among immigrant parent households seems to be high, but studies are showing that parents are not accessing services due to internal issues. Research has found that Hispanic children of immigrant parents are showing high developmental needs, but are the least likely to receive early intervention services (Johnson-Montoyama, Moses, Conrad-Hiebner \& Mariscal, 2016). Latino children of immigrant families have seen a decline in health due to the challenges caregivers face in addressing their children's basic needs (Capps, Horowitz \& Fortuny, 2009, p.2; Johnson-Montoyama et al., 2016; Kersey, Geppert \& Cutts, 2007; Lopez \& Velasco, 2011). Referred children of Hispanic non-US born caregivers are found to be least likely to receive services (Johnson-Montoyama, Moses, Conrad-Hiebner \& Mariscal, 2016).

Undocumented individuals seem to not be accessing services in the community (Finno-Velasquez, 2013). There is a high discrepancy in the access of health services amongst Latinos and their counterparts, with the undocumented immigrant population having the lowest rates of owning health insurance (Ortega, Fang, Perez, Rizzo \& Carter-Pokras, 2007, p 2354). A study by Ortegaet al. (2007) portrays language and culture as barriers experienced by undocumented individuals when attempting to access health services. There is this tremendous fear that on their way to take their children to school, or on their way to the clinic, or on their way to the store, they're going to be picked up and deported.

\section{Mental Health Services}

Other populations not seeking services are Immigrant Latino minorities. Prior research has found that immigrant Latino minorities are moderately depressed, yet they are not seeking mental health services (Tanner, Reboussin, Mann \& Song, 2014). One reason that immigrant Latino minorities are not seeking mental health services could be due to their undocumented immigration status. According to Shattell et al. (2014), there is a direct correlation between undocumented immigration status and feelings of fear and anxiety which influences individual's ability to access resources (Shattell, Hamilton, Starr, Jenkins \& Hinderliter, 2014, p. 360). Some Latinos even thought that mental health services were inaccessible to them due to their legal status (Shattell et al., 2014). This is an important issue because the Latino population is increasing at a rapid state and is predicted to consist of $24 \%$ in the US by 2050 (U.S. Census Bureau, 2004).

According to Kim et al. (2011), who examined the effect of limited English proficiency on mental health services among Latino and Asian immigrant adults with psychiatric disorders, there was a racial discrepancy of health insurance coverage in which Asian immigrants had a higher percentage of having insurance coverage. Asians were more than three times higher than those of second or first-generation Asians (10\% vs. $4 \%$ vs. $2 \%)$. Latino immigrants who had limited English proficiency (10\%) identified as having some type of psychiatric disorder. Researchers concluded that having poor/fair English speaking ability significantly decreased the odds of using mental health services in the total immigrant group as well as in the Latino immigrant group (Kim et al., 2011, p. 104). In the Asian immigrant group, however, limited English proficiency did not significantly affect mental health service use (Kim et al., 2011, p. 105). Further research has found that "Fear of deportation as a result of utilizing services represents a stark reality for undocumented immigrants and a recognized barrier to general health care. Participants explained that returning to their countries of origin meant losing access to HIV treatment and the ability to support their families" (Dang, Giordano \& Kim, 2012, p. 127). 


\section{Higher Education}

Higher education seems to be an unachievable dream for undocumented individuals. According to Diaz-Strong, Gomez, Luna-Duarte and Meiners (2011), undocumented individuals pursuing higher education deal with financial and social stressors that may pose a threat to accessing higher education. Throughout United States history, there has been much conversation regarding undocumented students pursuing higher education, yet many students decided to pursue their higher education in hope that a policy allowing them to work upon graduation will arise. Huber- Perez (2015) found that the transition out of school for these students was very difficult due to the conditions they face. Students in her research study called it a 'post-graduate trauma' (Huber- Perez, 2015). According to Diaz-Strong et al. (2011), they found that amongst families, that those families often help their student pay for part of their tuition. They found that undocumented students who have access to higher education was made possible through private scholarships, family contributions, and even making their own money working extra hours and taking fewer classes. These same researchers found that the thought of paying college tuition caused students to experience anxiety (p. 23). Undocumented individuals face many unique barriers including language, financial difficulties, lack of awareness and fear when accessing higher education, mental and health care services.

\section{Fostering Resilience}

Although fostering resilience is limited in research, resilience has shown to be a positive factor to undocumented students overcoming barriers. A research study done by Gamez, Lopez and Ocerton (2017) found three key components on how students were able to achieve success in their educational careers. They were able to achieve this by: 1.) The implementation of positive mentors, either an institutional mentor or a community mentor, that provided the guidance in their educational journey, 2.) The resiliency in oneself to strategize, and 3.)The internal motivation to challenge themselves and move forward (Gamez, Lopez \& Ocerton, 2017, p.52). Focusing specifically on resiliency, this study defined it as the personal strength, bravery, courage, or perseverance while overcoming challenges that individuals faced while pursuing higher education (Gamez, Lopez \& Overton, 2017). For example, undocumented students took ownership of their own stories by becoming their own advocates, lobbyists, and change agents in the aftermath of the DREAM Act's failure (Gamez, Lopez \& Overton, 2017). In addition, one example of resilient behavior was the ability to fund their own education by working one or multiple jobs (Gamez, Lopez \& Overton, 2017). Resilience was defined as a form of determination and persistence in the face of barriers and acceptance of the fact that these undocumented students might have to work harder to attain their degree than others, work multiple jobs, manage family issues, maintain academic requirements, seek healthcare from disparate sources, and overall, deal with the social and emotional issues of being labeled as undocumented or DACA (Gamez, Lopez \& Overton, 2017). Altogether, these undocumented students work twice as hard as the average student in order to become active members of society; many rely on their resilience to rebuild their self-esteem and self-worth to work towards a better future.

\section{Aims and Objective}

The purpose of this study is to assess how Deferred Action for Childhood Arrivals (DACA) recipients, eligible DACA non-recipients, and those who do not qualify for DACA are affected when accessing higher education, public health and mental health services. It is hypothesized that students who benefit from Deferred Action for Childhood Arrivals (DACA) are more likely and willing to access services than those who are not eligible for DACA and those who are eligible but are not DACA recipients.

\section{Method}

\section{Participants}

This study consists of a convenience sample of 102 participants at a California State University who identify as undocumented students through the university's Dream Center database and student records. Participants are 18 years or older. Seventy-one percent of the participants are female and $29 \%$ are male. One percent of the participants identify as Caucasian, $87 \%$ as Hispanic or Latino, $8 \%$ as Asian, and $4 \%$ identify as other. Eleven percent of the participants are freshmen, $20 \%$ are sophomores, $45 \%$ are juniors and $24 \%$ are seniors. Seventy-two percent of the participants identify as employed, $6 \%$ are currently unemployed, $9 \%$ have never been employed, $5 \%$ are self-employed and $9 \%$ reported to be currently unemployed, but actively looking. 
One percent of the participants live on-campus, $29 \%$ live off-campus, $70 \%$ live at home, and no participants identified as not having stable housing. All participants are undocumented, but only $76 \%$ identify as eligible recipients of DACA, while the other $24 \%$ are not benefiting from DACA as they report identifying as either DACA eligible, but not current recipients or non-DACA eligible.

\section{Measures}

Survey was used to collect data. The 40-item questionnaire was divided into four sections: (1) Demographics such as age, gender, race, and current grade level; (2) Experience in accessing health services (yes or no); (3) Experience in accessing mental health services (yes or no); (4) Experience in accessing higher education (yes or no) and 10 follow up questions. The researchers created the questionnaire based on previous literature and other research findings.

\section{Design}

This research is a mixed method study that uses a self-report survey. The survey was administered to participants via Qualtrics.

\section{Procedure}

This study uses a survey to understand the effects of the legal status of undocumented students on their access to services, such as health care, mental health and higher education. Prior to the administration of the survey, the researchers of this study complied with all necessary documentation for approval of this research study by the California State University, Institutional Review Board (IRB). Following IRB approval, the 40-item questionnaire was emailed to the students in the CSU Dream Center database by the Dream Center coordinator, establishing confidentiality for the participants. A consent form addressing the purpose of the study accompanied the email sent to the students as well as provided the contact information for the researchers of the study. Students who participated in this study were encouraged to follow the link to the questionnaire, which directed them to Qualtrics. Participants were encouraged to answer all the questions and notified of the estimated completion time. Participants were informed that they may decline to answer any question on the questionnaire. Qualtrics was used to collect the data recorded by close-ended questions while the answers to the open-ended questions were reviewed to find relevant themes.

\section{Data Analysis}

Data gathered by Qualtrics was analyzed through the SPSS software by conducting a Chi-Square test for independence for documentation status as the independent variable (1) DACA recipients, (2) DACA eligible, but not recipients, and (3) DACA non-eligible fell into the demographics patterns; and (4) access to health services, (5) access to mental health services, and (6) access to higher education as the dependent variables. Common themes were reviewed and analyzed through the use of line-by-line coding in which the researchers first read and reviewed each response to the open-ended questions and then coded and organized similar answers into concepts and themes.

\section{Results}

\section{Undocumented Student's Access to Health Care Services}

From the $76 \%$ of the participants who identify as DACA recipients, more than half $(61 \%)$ report having some type of health insurance, while those who identified as eligible but not current DACA recipients, as well as nonDACA eligible individuals report having no type of health care. A significant relationship was identified with documentation status and having some type of health care, $X^{2}(2, \mathrm{~N}=102)=27.9$. The majority of the DACA recipients $(85 \%)$ report feeling comfortable when accessing health care services, while $100 \%$ of those who do not have DACA as a protective status report not feeling comfortable when accessing health care services. This finding was statistically significance as those who have DACA as a protective status are more likely to access health care services than those who have no protective status, $X^{2}(2, \mathrm{~N}=100)=55, p<.001$. One hundred percent of the participants who identify as familiar with an available healthcare provider are DACA recipients and more than half of the DACA recipients $(57 \%)$ are familiar with an available health care provider. There is statistical significance in documentation status and familiarity with health care providers as $100 \%$ of participants who identify with no protective status as non-DACA eligible including eligible, but not current recipients report not being familiar with an available healthcare provider, $X^{2}(2, \mathrm{~N}=100)=23.08, p<.001$. 
Sixty-one percent of DACA recipients report having a health care provider while all the self-identifying undocumented students with no protective status report having no health care provider, $X^{2}(2, \mathrm{~N}=101)=26.97, p$ $<.001$. Less than half of those who report having a health care provider report attending to their health care provider regularly with $28 \%$ of DACA recipients and $0 \%$ of those with no protective status, $X^{2}(4, \mathrm{~N}=101)=$ 91.85, $p<.001$. Less than half of the participants $(26 \%)$ report having a good relationship with a health care provider including only $33 \%$ of DACA recipients, $X^{2}(4, \mathrm{~N}=100)=30.56, p<.001$. Thirty-one percent of all participant's report communicating well with their health care provider including less than half of DACA recipients (39\%), and only $30 \%$ of all participant's report enjoying visiting a health care provider with only $39 \%$ of DACA recipients.

Fifteen percent of DACA recipients who do not feel comfortable accessing health care services and those who identify as having no protective status report having a lack of income or knowledge to find affordable services which deters them from feeling comfortable accessing services. Fear is also perceived as a common deterrent for these individuals when accessing health care services as the participants who deny feeling comfortable when accessing services report not being fond of giving out their personal information to clinics as this exposes their legal status. The participants with no protective status report having no relationship with health care providers as the participants of this study report refusing to attend to a health care provider due to lack of insurance or knowledge of available resources. As reported by the participants in this sample, it is also very common for this population to wait until their health requires them to attend to urgent care or the emergency room, making it difficult for the respondents to build rapport with the health care provider.

\section{Undocumented Student's Access to Mental Health Services}

Accessing mental health services can be difficult for various populations and culture groups, but even more difficult for those who identify as undocumented students. About one third of the participating students (34\%) report being familiar with available mental health services. About half of those who report as familiar with available mental health services (45\%) identify as DACA recipients, while $100 \%$ of those with no protective status report not being familiar with available mental health services resulting in statistical significance as $X^{2}(2$, $\mathrm{N}=102)=16.4, p<.001$. More than half of the participants $(60 \%)$ who identify as DACA recipients report feeling comfortable accessing mental health services, but only $74 \%$ of all DACA recipients identify as comfortable accessing mental health services. One hundred percent of participants with no protective status report feeling uncomfortable accessing mental health services resulting in statistical significance, $X^{2}(2, \mathrm{~N}=96)=33.8 \mathrm{p}$ $<.001$, as having a protective status creates a sense of safety when accessing services including mental health services. Within the participating sample, less than a fourth $(22 \%)$ report ever receiving mental health services. One hundred percent of those who report as having received mental health services identify as DACA recipients. Thirty percent of DACA recipients in the sample report having received mental health services at some point in their lives. One hundred percent of those who identify as non-DACA eligible or eligible, but not current recipients report never receiving mental health services which establishes statistical significance between documentation status and mental health services, $X^{2}(2, \mathrm{~N}=102)=9.14, p=001$. Only 5\% of all participants report currently receiving mental health services with $100 \%$ of them identifying as DACA recipients, which does not constitute as statistically significant, $X^{2}(2, \mathrm{~N}=102)=1.96, p=0.38$. Only $19 \%$ of the participants reported interest in seeking mental health services as it relates to their undocumented immigration status.

Participants who do not feel comfortable accessing mental health services report lack of knowledge of available mental health services, fear of releasing personal information and being perceived as an embarrassment to their family as deterrents to accessing mental health services. These participants reported symptoms of depression and anxiety associated with the Trump Administration due to a reported increase in feelings of fear and worry towards their personal safety and that of their families. Various respondents identified a stigma associated with receiving mental health services in their families, which prevents them from seeking services.

\section{Undocumented Student's Access to Higher Education}

Previous research suggests undocumented students face many difficulties in accessing higher education opportunities. Ninety-eight percent of participant's report completing High School and receiving a High School diploma from the sample population of DACA recipients, and 87\% of non-DACA eligible participants. Sixteen percent of the participating sample reports receiving a General Education Document (GED) and 9\% report receiving a High School diploma from an accredited Adult School Program. 
Our current research reports $95 \%$ of the participants are aware of available financial aid opportunities. One hundred percent of DACA recipients and those who are eligible but not current DACA recipients are aware of available financial aid, while only $67 \%$ of those who are non-DACA eligible are aware of these opportunities, establishing a statistical significance, $X^{2}(2, \mathrm{~N}=102)=30.5, p<.001$. One hundred percent of DACA recipients and participants who are eligible, but not current recipients report currently receiving financial aid, while less than half $(47 \%)$ of non-DACA participants report currently receiving some type of financial aid displaying statistical significance where being a recipient or potential recipient of DACA contributes to accessing financial aid, $X^{2}(2$, $\mathrm{N}=102)=50.35, p<.001$. Ninety-seven percent of the participating sample reports pursuing higher education immediately after completing high school with $80 \%$ being DACA recipients, $9 \%$ eligible, but not current DACA recipients and $11 \%$ non-DACA eligible participants with a statistical significance, $X^{2}(2, \mathrm{~N}=101)=19.2, p<.001$ in which DACA recipients were more likely to pursue higher education immediately after completing high school. Eighty-eight percent of the participants report being the first in their families to attend college; 87\% identifying as DACA recipients, $10 \%$ as eligible, but not current DACA recipients and 3\% as non-DACA eligible. DACA students are more likely to pursue and engage in higher education opportunities, $X^{2}(2, \mathrm{~N}=102)=78.9, p<.001$.

Undocumented students face similar struggles and concerns when accessing higher education similar to accessing health care and mental health services. As reported by the participants in this study, lack of resources including income plays a vital role in pursuing higher education opportunities. Financial insecurity is a burden shared by many participants that have benefitted from the limited financial aid resources available to them including the Dream Grant. Fear seems to be a common factor in the lives of the undocumented students regardless of protective status as participants reported feelings of uneasiness and worry when encountering a new space where they are unfamiliar with the services and available opportunities.

\section{Fostering Resilience}

Participants also reported that they were taking care of themselves during this political climate on immigration and DACA. Most participants reported that they keep busy, stay focused and are moving forward with their lives. Others stated they are seeking out lawyers for consultation in case they need legal assistance when a dramatic change happens. Participants also reported that they are staying home as much as possible, going out only for work and school. Their fear and anxiety of being deported has taken a toll on them, so they would rather stay home and feel safe. Participants also reported that they are working hard and obeying all government rules and laws in order to not be categorized as a 'dangerous immigrant'.

Participants were asked based on age groupings and the categories of receiving services, "how did they survive working", how easy or hard was it "accessing health services" or "mental health services". Age groups were 1821, 22-25, and 26-32. Our sample population of 18-21 year olds reported that since applying for DACA they felt that going to school made it easier for them to complete their education, they felt they had a better life, and they had access to health care through the university health system, which made them feel important. Participants also reported having anxiety when looking for a job because they did not have green cards. Participants who are currently employed reported always having the fear of police raiding their place of work. Others reported not needing health care nor a job prior to DACA since they were in high school when they were accepted by DACA. Participants reported that living at home with supportive parents who supported them financially; they reported they didn't need counseling or health care services. Others reported that even if they wanted employment, it would be extremely hard since they did not have work permits (green cards). If they did work, it would most likely be in a family business or for an employer that can pay them under the table (cash).

DACA students in the age range of 22-25 reported that they had barely heard of DACA being implemented in 2012. Many said they were privileged to only focus on school and work thanks to being a DACA recipient. Participants knew they were undocumented, but were unaware of the barriers and opportunities they could be striped of. Some knew about what life was without DACA and were not afraid to confront those barriers. Others reported that before DACA they attended community college, since that was the most affordable option available to them. After applying for DACA, they were now able to benefit from DACA and the Dream Act, by allowing them to transfer to either the University of California or California State University Systems.

Most of the participants reported having Emergency Medical Health Care which only gives them the option of going to the Emergency room, not access to a particulate health care provider. Most of the participants also talked about how they would drive without a valid license, or just take public transportation, which involved spending lots of time commuting and less time for work or school and making them at high risk for being deported. 
DACA students ages 26-32 reported having more hardships before DACA. Some participants reported working by collecting recycle cans and bottles. Some stated that they had to work under the table for cash, and acquired fake social security numbers or identification cards. Many participants reported driving without a license, being cautious of police enforcement and following traffic laws. Most of them felt unsafe, but had to find a way to survive and keep moving on with life. Most of the participants in this age group reported having used health care centers at school or Planned Parenthood. Some would avoid visiting the doctor when very ill due to mistrust and fear that the doctor would report them to the police.

\section{Discussion}

Undocumented students are a major group known to be vulnerable and understudied in their access to public health care, mental health services and higher education. Results of the present study revealed a significant difference between students who identified as DACA recipients, eligible but not current recipients, and nonDACA recipients in terms of their access to a health care provider. The majority of the DACA recipients $(85 \%)$ report feeling comfortable when accessing health care services, while $100 \%$ of those who do not have DACA as a protective status report not being comfortable when accessing health care services. Although more than half of DACA recipients are comfortable in accessing health care services, students with no protective status do not feel comfortable accessing a health care provider. These findings align with previous research, suggesting that undocumented people appear to not access health care services that are available in the community (FinnoVelasquez, 2013). Results also found a statistical significance in documentation status and being familiar with a health care provider, as $100 \%$ of participants who identify with no protective status as non-DACA eligible and eligible, but not current recipients report not being familiar with an available healthcare provider. Also, $15 \%$ of DACA recipients who do not feel comfortable accessing health care services and those who do not identify having a protective status report not having the income or knowledge to seek out health care services. Fear of disclosing legal status appeared to be a common factor within this particular sample when attempting to access services. These findings support prior research suggesting that people are not accessing public health services due to internal issues (Johnson-Montoyaet al., 2016).

The undocumented population is rapidly growing and is predicted to consist of $24 \%$ by 2050 (U.S. Census Bureau, 2004, 2010, 2017). This statistic led the researchers to include mental health services as it pertains to the undocumented population based on past research which suggests that Latino minorities appeared to be moderately depressed (Tanneret al., 2014). Our current sample in this research found that less than half of the participating students (34\%) report being familiar with available mental health services. From the $34 \%$ of individuals being familiar with mental health services, $44 \%$ identified as DACA recipients, while $100 \%$ of the participants not having a protective status report not being familiar or comfortable accessing mental health services. These findings align with past research suggesting that Latinos think that there are no mental health services available to them due to their legal status (Shattell, Hamilton, Starr, Jenkins \& Hinderliter, 2014).

Our research found that within the overall participating sample, only $23 \%$ of individuals report ever receiving mental health services, with $100 \%$ of the individuals who did receive these services also identified as DACA recipients. Furthermore, $19 \%$ of the participants reported interest in seeking mental health services as it relates to their undocumented immigration status. These findings align with past research suggesting that the label of 'Undocumented' rises feelings of fear, depression and anxiety (Shattellet al., 2014; Tanner al., 2014). Based on these findings, it appears that this particular population is not seeking mental health services due to lack of knowledge of services available to them, fear of disclosing legal status, and being stigmatized by family and community members for seeking mental health services. These findings are also supported by past research in which other participants reported fear of deportation which prevented them from accessing mental health services (Dang, Giordano \& Kim, 2012).

This present research found that $98 \%$ of the participating sample report completing high school and receiving a high school diploma, with $100 \%$ being DACA recipients, $100 \%$ being eligible for DACA and $87 \%$ being nonDACA eligible participants. These findings support past research and point out the amount of resilience in this particular community. Perez-Huber (2015) found that although there was a lot of negativity and stigma around undocumented students pursuing a higher education, this did not prevent students from pursuing their dreams of obtaining a higher education in hope of a policy being developed which would allow them to legally work upon receiving a degree. 
Based on qualitative results, researchers found that undocumented students face similar struggles and concerns when accessing higher education and mental and health care services. Researchers found that there are many barriers involved as it pertains to undocumented students accessing higher education; "Not having a sufficient income to pay for tuition and books, working double jobs in order to assist family members, lack of financial aid knowledge, not knowing how to access financial aid opportunities and deadlines (Diaz-Strong, Gomez, LunaDuarte \& Meiners, 2011)". Participating undocumented students report fear of disclosing their legal status to school administration and other students at the university. These statements align with past research suggesting that undocumented individuals pursuing a higher education have to deal with financial and social stressors (DiazStrong et al., 2011).

\section{Limitations}

Findings in this present study should be interpreted with the following limitations. Our participants reside in the Southern California area and are current college students at a four-year university, $1 \%$ being Caucasian, $87 \%$ Hispanic/Latino, $8 \%$ Asian, and $4 \%$ identifying as other. Therefore, our findings may not be generalizable to only one race of undocumented students across the United States. Also, participants were allowed to skip questions while still being able to complete the survey. Not all students provided personal experiences, and there might be a difference between students who provided personal experiences as opposed to those that did not. All our participants came from The Dream Center on campus, meaning that they are aware of some sort of resource such as The Dream Center which provides them with further knowledge on resources available. Lastly, researchers did not take into account the barrier of language when creating the survey as it pertains to participants accessing services in the community.

\section{Implications for Future Research}

This study identifies unique barriers in accessing health care, mental health services and higher education involving undocumented students which include fear of deportation and disclosure of legal status, lack of financial stability, and lack of knowledge when it comes to services available to them and stigmatization. Our study suggests that those who identified as current DACA recipients were more prone to accessing services and had a clearer understanding of the services available to them, in comparison to those who identified as eligible but not recipients and non-DACA recipients. Researchers found it interesting that the added layer of having some sort of protective status such as being DACA recipients allowed for more openness when accessing resources.

However, the overall factor that DACA recipients and non-DACA recipients shared was the same concerns of fear and lack of financial stability. Intervention strategies to promote access to health care, mental health services and higher education need to reflect the reality of the state and Nation which will take into account that these individuals may not be receiving the knowledge needed. Interventions such as PSA's, Billboards, and media must be utilized when attempting to engage this population to seek out services. Informational meetings for those undocumented students wanting to pursue a higher education must be held in order to advise them of resources, financial aid, and specialized programs offered through the CSU and UC systems.

As a result of this study, we identified areas in which further research needs to be done. These areas include focusing on undocumented students attending a community college, family members of students pursuing a higher education and evaluating if the actions these students are taking reflect on the actions their family members take when accessing services in the community.

\section{Conclusion}

There is a substantial debate in the U.S. about how to frame the issue of undocumented individuals and how best to respond to the objections of those against undocumented individuals. This study revealed that the use of health are, mental health services and higher education among a sample of undocumented students living in California is very limited due to fear, lack of knowledge and income. Our data suggests that the ability to navigate the health care, mental health and higher education system is a hardship for undocumented individuals, which may often lead them to not seek services. The reality here is that the number of undocumented individuals living in the U.S. is rising and will keep on rising within the next few years (U.S. Census Bureau, 2004, 2010, 2017). Our research suggests that it is imperative for us as a community and country to understand the barriers to health care, mental health services, and higher education access among this particular population in order to better serve and develop effective interventions that will assist them. 


\section{References}

Avila, R. M. \& Bramlett, M. D. (2013). Language and immigrant status effects on disparities in Hispanic children's health status and access to health care. Maternal and Child Health Journal, 17(3), 415-423. doi:10.1007/s10995-012-09889

Berk, M. \& Schur, C. (2001). The effect of fear on access to care among undocumented Latino immigrants. Journal of Immigrant Health, 3(3), 151-156.

Capps, Horowitz, \& Fortuny, (2009). Household food insecurities threats to children's well-being, American Psychological Association, Washington D.C.

Dang, B. N., Giordano, T. P. \& Kim, J. H. (2012). Sociocultural and structural barriers to care among undocumented Latino immigrants with HIV infection. Journal of Immigrant And Minority Health, 14(1), 124-131. doi:10.1007/s10903011-9542-x

Diaz-Strong, D., Gomez, C., Luna-Duarte, M. \& Meiners, E. (2011). Purged: Undocumented students, financial aid policies, and access to higher education. Journal of Hispanic Higher Education, 10(2), 107-119.

Finno-Velasquez, M. (2013). The relationship between parent immigration status and concrete support service use among Latinos in child welfare: Findings using the national survey of child and adolescent well-being (nscawii). Children and Youth Services Review, 35(12), 2118-2127.

Flores, G., Tomany-Korman, S., C. \& Abren, M. (2007). Uninsured Latino children: A call to action: In reply. Pediatric, 119 (5): 1034-1035.

Gamez, R., Lopez, W. \& Overton, B. (2017). Mentors, Resiliency, and Ganas: Factors influencing the success of DOCAmented, undocumented, and immigrant students in higher education. Journal of Hispanic Higher Educator, 16(2), 144-161.

Gonzales, R., Terriquez, V. \& Ruszczyk, S. (2014). Becoming dacamented: Assessing the short-term benefits of deferred action for childhood arrivals (daca). American Behavioral Scientist, 58(14), 1852-1872.Huber, L., (2015). "como una jaula de oro" (it's like a golden cage): The impact of daca and the california dream act on undocumented chicanas/latinas. Chicano-Latino Law Review, 33, 91-129.

Johnson-Motoyama, M., Moses, M., Conrad-Hiebner, A. \& Mariscal, E. S. (2016). Development, CAPTA part C referral and services among young children in the U.S. Child welfare system: Implications for Latino children. Child Maltreatment, 21(3), 186-197. doi:10.1177/1077559516630831.

Kersey, M., Geppert, J. \& Cutts, D., B. (2007). Hunger in young children of Mexican immigrant families. Public Health Nutrition, 10 (4): 390-395.

Kim, G., Loi, C. A., Chiriboga, D. A., Jang, Y., Parmelee, P. \& Allen, R. S. (2011). Limited English proficiency as a barrier to mental health service use: A study of Latino and Asian immigrants with psychiatric disorders. Journal Of Psychiatric Research, 45(1), 104-110. doi:10.1016/j.jpsychires.2010.04.031.

Martinez Tyson, D., Arriola, N. B. \& Corvin, J. (2016). Perceptions of depression and access to mental health care among Latino immigrants: Looking beyond one size fits all. Qualitative Health Research, 26(9), 1289-1302. doi:10.1177/1049732315588499.

Nandi, A., Galea, S., Lopez, G., Nandi, V., Strongarone, S. \& Ompad, D. C. (2008). Access to and Use of Health Services Among Undocumented Mexican Immigrants in a US Urban Area. American Journal Of Public Health, 98(11), 2011-2020.

Ortega, A., Fang, H., Perez, V., Rizzo, J., \& Carter-Pokras, O. (2007). Health care access, use of services, and experiences among undocumented Mexicans and other Latinos. Archives of Internal Medicine, 167(21), 2354.

Hispanic Trends. (2017). Pew Research Center. Retrieved from: http:www.pewhispanic.org Lopez, M., N., Velasco, G., (2011). Hispanic poverty rate highest in new supplemental census measure. Pew Hispanic Center, Washington D. C.

Perez, H. (2015). Mexican bandity. Qualitative Inquiry, 21(3): 223-238.

Pew Research Center. (2017). Pew Research Center's Hispanic tends project. Retrieved from http://www.pew hispanic.org/.

Schmid, C., (2013). Undocumented Childhood Immigrants, the Dream Act and Deferred Action for Childhood Arrivals in the USA. International Journal of Sociology and Social Policy, 33(11/12), 693-707.

Shattell, M. M., Hamilton, D., Starr, S. S., Jenkins, C. J. \& Hinderliter, N. A. (2008). Mental health service needs of a Latino population: A community-based participatory research project. Issues in Mental Health Nursing, 29(4), 351-370. doi:10.1080/01612840801904316.

Tanner, A. E., Reboussin, B.A., Mann, L., Ma, A., Song, E., Alonzo, J. \& Rhodes, S. D. (2014). Factors influencing health care access perceptions and care-seeking behaviors of immigrant Latino sexual minority men and transgender individuals: Baseline findings from the HOLA Intervention Study. Journal of Health Care for the Poor and Underserved, 25(4), 1679-1697. doi:10.1353/hpu.20 14.0156

U.S. Census Bureau (2004, 2010, 2017). The Foreign Born Population in the United States. Washington, DC: U.S. Census Bureau. 
Instrumentation Survey

\section{Appendix A}

Q1 Gender

O Male (1)

O Female (2)

other (3)

Q2 Race

O Caucasian (1)

O Hispanic/Latino (2)

O African American (3)

O Asian (4)

O Other (5)

Q3 Age

Q4 Current grade level

O Freshman (1)

O Sophomre (2)

O Junior (3)

O Senior (4)

Q5 Units completed to date

Q6 What is your Major?

Q7 What is your Minor? (If you do not have a Minor, please enter "N/A.")

Q8 Employment Status

O Employed (1)

O Currently Unemployed (2)

O Never Employed (3)

O Self-Employed (4)

Unemployed, but actively looking (5)

Q9 Current living conditions

O Live on-campus (1)

O Live off-campus (2)

L Live at home (3)

O No stable housing (4)

Q10 If you live off-campus, how many miles do you commute each day?(If this does not apply to you, please enter "N/A.")

Q11 Are you eligible for Deferred Action for Childhood Arrivals (DACA)?

O Yes (1)

O No (2)

Q12 Are you a current DACA recipient?If yes, please enter the date or year you became a recipient.

O Yes (1)

No (2)

Q13 Are you eligible for DACA, but not currently a recipient?Please explain your answer.(Example: "I was unable to renew my DACA due to lack of income.")

O Yes (1)

O No (2) 
Q14 Are you non-DACA eligible?Please explain your answer.(Example: "No, I do not meet DACA requirements.")

O Yes (1)

O No (2)

Q15 Do you have Health Insurance?

O Yes (1)

No (2)

Q16 Do you feel comfortable accessing health care services?Please explain your answer.(Example: "No, I don't like to give out my personal information at the clinics.")

O Yes (1)

O No (2)

Q17 Are you familiar with an available health care provider for you?

O Yes (1)

O No (2)

Q18 When was the last time you attended your health care provider? (Date or year)

Q19 Do you currently have a health care provider?

O Yes (1)

O No (2)

Q20 Do you attend your healthcare provider regularly?

O Yes (1)

O No (2)

O N/A (3)

Q21 Do you have a good relationship with your healthcare provider?Please explain your answer.(Example: "Yes, but it's hard to communicate with my Doctor through interpreter.")

O Yes (1)

O No (2)

O N/A (3)

Q22 Do you communicate well with you health care provider?

O Yes (1)

O No (2)

O N/A (3)

Q23 Do you enjoy visiting your health care provider?

O Yes (1)

O No (2)

O N/A (3)

Q24 Is there any additional information you would like to provide?

Q25 Are you familiar with mental health services available to you?

O Yes (1)

O No (2)

Q26 Do you feel comfortable accessing mental health services? Please explain your answer. (Example: No, mental health services are a sign of weakness.")

O Yes (1)

O No (2)

Q27 Have you received mental health services in the past?

O Yes (1)

O No (2) 
Q28 Are you currently receiving mental health services?

O Yes (1)

O No (2)

Q29 If you are seeking mental health services, is it related to your immigration status?Please explain your answer. (Example: "I feel depressed. My family is in Mexico.")

O Yes (1)

No (2)

Q30 Is there any additional information you would like to provide?

Q31 Are you aware that as a student you are eligible for financial assistance?

O Yes (1)

No (2)

Q32 Are you currently receiving any type of financial aid?

O Yes (1)

O No (2)

Q33 What was your experience when entering CSUN as it relates to your immigration status?(Example: "Difficult, paying for tuition was hard because I didn't qualify for financial aid." )

Q34 Did you complete High School and receive your High School diploma?

O Yes (1)

O No (2)

Q35 Do you have a GED?

O Yes (1)

O No (2)

O N/A (3)

Q36 Do you have a High School diploma from an accredited adult school program?

O Yes (1)

O No (2)

O N/A (3)

Q37 Did you pursue higher education straight after High School?

O Yes (1)

O No (2)

Q38 Are you the first person to attend college in your family?

O Yes (1)

O No (2)

Q39 If you identify as a graduate student, are you the first in your family to get a graduate level degree?

○ Yes (1)

O No (2)

O N/A (3)

Q40 Is there any additional information you would like to provide? 